\title{
Background styles in systematic review articles: a cross-sectional study protocol
}

Authors:

Yuki Kataoka, MD, MPH, DrPH ${ }^{1), 2), 3), 4)}$, Shunsuke Taito, PT PhD ${ }^{3), 5)}$, Sachiko Yamamoto-Kataoka,

MD, MPH, PhD ${ }^{6)}$, Yasushi Tsujimoto, MD, $\mathrm{MPH}^{3), 6), 7)}$, Hajime Yamazaki, MD, PhD ${ }^{2)}$, Toshi A.

Furukawa, $\mathrm{MD}, \mathrm{PhD}^{8)}$

\section{Affiliations:}

1 Hospital Care Research Unit, Hyogo Prefectural Amagasaki General Medical Center,

Higashinaniwa-cho 2-17-77, Amagasaki 660-8550 JAPAN

2 Department of Community Medicine in the Graduate School of Medicine, Kyoto University,

Yoshida Konoe-cho, Sakyo-ku, Kyoto 606-8501, JAPAN

3 Systematic Review Workshop Peer Support Group (SRWS-PSG), Japan

4 Department of Respiratory Medicine, Hyogo Prefectural Amagasaki General Medical Center,

Higashinaniwa-cho 2-17-77, Amagasaki 660-8550 JAPAN

5 Division of Rehabilitation, Department of Clinical Practice and Support, Hiroshima

University Hospital, Kasumi 1-2-3, Minami-ku, Hiroshima, 734-8551 Japan 
6 Department of Healthcare Epidemiology, Graduate School of Medicine and Public Health,

Kyoto University, Yoshida Konoe-cho, Sakyo-ku, Kyoto 606-8501, JAPAN

7 Department of Nephrology and Dialysis, Kyoritsu Hospital, 16-5 Chuo-cho, Kawanishi,

Hyogo 666-0016, Japan

8 Department of Health Promotion and Human Behavior, School of Public Health in the

Graduate School of Medicine, Kyoto University, Yoshida Konoe-cho, Sakyo-ku, Kyoto

606-8501, Japan

\section{Corresponding author:}

Toshi A Furukawa

Department of Health Promotion and Human Behavior, School of Public Health in the Graduate

School of Medicine, Kyoto University, Yoshida Konoe-cho, Sakyo-ku, Kyoto 606-8501, Japan

Phone: $+81-75-753-9491$

Fax: +81-75-753-4641

Email: furukawa@kuhp.kyoto-u.ac.jp 
Abstract

Background: The background section of a medical journal article has the important

function to communicate readers the value of the research question. However, little is

known about how authors describe their "niche" to emphasize the importance of their

research question. This study aims to examine the methods the authors use in order to

delineate their niche in systematic reviews (SR).

Methods: We will conduct a cross-sectional study. We will include Original SR articles

published in top 50 journals in MEDICINE, GENERAL \& INTERNAL category in

Journal Citation Reports 2018. We will conduct content analysis of background sections.

The primary outcome will be whether the article was published in top 10 journal or not.

We will use chi-squared test and logistic regression analysis. The primary analysis will

be logistic regression predicting publication in high impact journals, with covariates.

Two-tailed $\mathrm{p}$ values will be considered statistically significant if less than 0.05 .

Discussion: This is the first study to investigate the influence of what to present and not present in the backgrounds section to be accepted in the highly cited journals among SR articles. 


\section{Backgrounds:}

The background section of a medical journal article has the important function to communicate readers the value of the research question. There are many textbooks and review articles on how to write it based on expert opinions (1-3). In addition, there are several analyses that examined its structure in medical research articles. The basic structure of the background section may be characterized as follows: "establishing a territory", "establishing a niche", and "occupying the niche" $(4,5)$.

However, little is known about how authors describe their "niche" to emphasize the importance of their research question. This study aims to examine the methods the authors use in order to delineate their niche in systematic reviews (SR). We have focused on SRs because SRs are the most important research design, in terms of practicing evidence-based medicine (6).

\section{Meshods:}

\section{Protocol:}

We followed the reporting guideline of meta-epidemiological study to prepare this protocol (7). We will publish this protocol in medRxiv (https://www.medrxiv.org/). 
Study design:

We will conduct a cross'sectional study.

Eligibility criteria:

Original SR articles published in top 50 journals in MEDICINE, GENERAL \&

INTERNAL category in Journal Citation Reports 2018 (8). We show the lists in table 1.

We will include articles published in 2018. We will include all SR articles irrespective of included primary study designs. The definition of SR is "a scientific investigation that focuses on a specific question and uses explicit, prespecified scientific methods to identify, select, assess, and summarize the findings of similar but separate studies." (9).

We will exclude Cochrane Reviews or the U.S. Preventive Services Task Force review because their backgrounds styles are prespecified by the respective organizations and different from usual original articles $(10,11)$.

Information Sources:

PubMed, Web of Science

Search:

We will search PubMed. The details of search formula are shown in Table 2A, and 2B. 
Study selection:

One review author (YK) will confirm whether the articles are SR or not.

Exposures:

Four aspects that one can emphasize about one's research question in the background section may be summarized as follows: "novelty", "scope", "quality", and "update".

"Novelty" means a completely new research question.

"Scope" means that there are reports related to the research question, but authors expanded or limited the PICO.

"Quality" means that there are reports related to the research question, but there were methodological flaws.

"Update" means that there were same reports, but the search date was new.

We will conduct content analysis of the first 10 articles independently by four review authors (YK, ST, YT, or HY). We will develop a detailed guide from the initial review. We will resolve disagreements through the discussion, after that two of four review authors will conduct content analysis of the rest. We will resolve disagreements through the discussion. If necessary, another third reviewer will act as an arbiter. We will add other categories through the review if necessary. We will assess the agreement with kappa 
values.

Primary outcome:

The primary outcome will be whether the article was published in top 10 journal or not.

Data items:

Details are shown in Table 3. Considering that papers published in top journals will have many citations, we defined confoundings following previous studies which investigated the prognostic factors for increased citations (12-15). We will retrieve some data from Web of Science application programming interface using Python 3.7.4 software program (Python Software Foundation, De, USA).

\section{Statistical analysis:}

We will use descriptive statistics to summarize. We will use chi-squared test and logistic regression analysis. The primary analysis will be logistic regression predicting publication in high impact journals, with covariates as listed above. Two-tailed p values will be considered statistically significant if less than 0.05 . We will use Stata ver. 16.0 (StataCorp LLC, College Station, Texas, United States of America). We determined the sample size as below: we will use 4 exposures and 5 confoundings. We need 90 events for 
the validity of the logistic model (16). We will randomly select 90 articles from the top 10 journals and 90 articles from the $11^{\text {th }}$ to $50^{\text {th }}$ journal as control.

\section{Discussion:}

This is the first study to investigate the influence of what to present and not present in

the backgrounds section to be accepted in the highly cited journals among SR articles.

There are several limitations. We will not assess the methodological quality of each articles due to the difficulty to score the quality in single measurement. For example, AMSTAR 2 (17), which is the most famous assessment tool, only accounts for intervention SRs. We will not take into account the clinical significance of the review, which is a confounding factor, but it is difficult to evaluate on one scale.

The results of this study will be a good help for systematic review authors not only when they write the background section, but also when they think about research questions. 
medRxiv preprint doi: https://doi.org/10.1101/2020.01.19.20018127; this version posted January 24, 2020. The copyright holder for this preprint (which was not certified by peer review) is the author/funder, who has granted medRxiv a license to display the preprint in perpetuity.

It is made available under a CC-BY-ND 4.0 International license .

Table 1. Top 50 journals in MEDICINE, GENERAL \& INTERNAL category categorized in Journal Citation Reports 2018

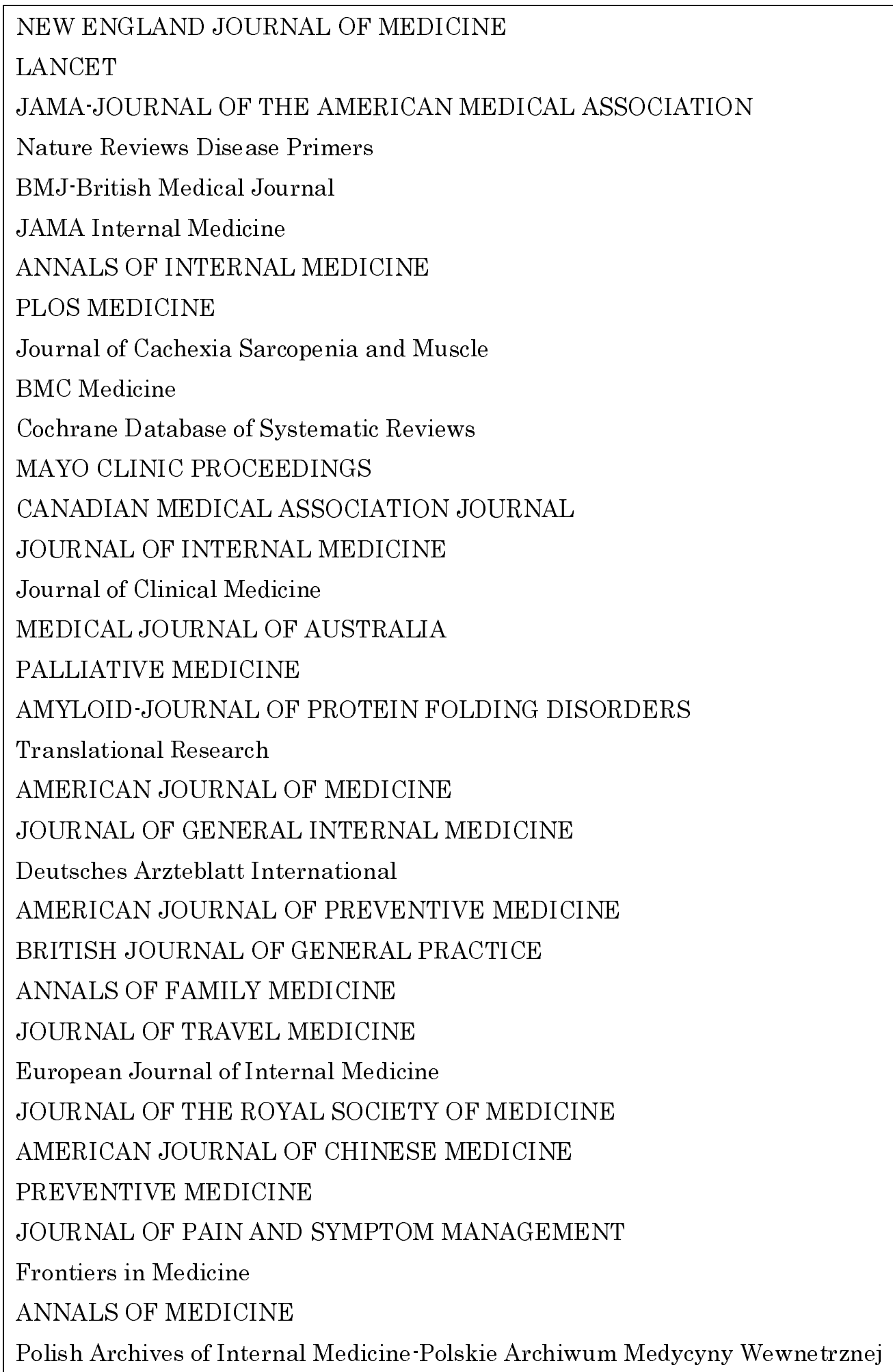


JOURNAL OF THE FORMOSAN MEDICAL ASSOCIATION

BRITISH MEDICAL BULLETIN

EUROPEAN JOURNAL OF CLINICAL INVESTIGATION

PAIN MEDICINE

UPSALA JOURNAL OF MEDICAL SCIENCES

MEDICAL CLINICS OF NORTH AMERICA

KOREAN JOURNAL OF INTERNAL MEDICINE

QJM-AN INTERNATIONAL JOURNAL OF MEDICINE

INTERNATIONAL JOURNAL OF CLINICAL PRACTICE

AMERICAN FAMILY PHYSICIAN

Journal of the American Board of Family Medicine

Diagnostics

MINERVA MEDICA

BMC Family Practice

Archives of Medical Science

BMJ Open 
Table 2A Search formula of top 10 journals

\begin{tabular}{|l|l|l|}
\hline & formula & $\begin{array}{l}\text { number of } \\
\text { references }\end{array}$ \\
\hline$\# 1$ & 2018[pdat] & 1329623 \\
\hline$\# 2$ & "Systematic Review"[Publication Type] & 117216 \\
\hline "N Engl J Med"[journal] OR "Lancet"[journal] OR "JAMA"[journal] OR \\
"Nat Rev Dis Primers"[journal] OR "BMJ"[journal] OR "JAMA Internal \\
$\begin{array}{l}\text { Medicine"[journal] OR "Ann Intern Med"[journal] OR "PLoS } \\
\text { Med"[journal] OR "J Cachexia Sarcopenia Muscle"[journal] OR "BMC } \\
\text { Med"[journal] }\end{array}$ & 412907 \\
\hline$\# 4$ & $\# 1$ AND \#2 AND \#3 & 131 \\
\hline
\end{tabular}

Table 2B Search formula of top 12 to 50 journals*

\begin{tabular}{|l|l|l|}
\hline & formula & $\begin{array}{l}\text { number of } \\
\text { references }\end{array}$ \\
\hline$\# 1$ & 2018 [pdat] & 1329623 \\
\hline$\# 2$ & "Systematic Review"[Publication Type] & 117216 \\
\hline 3 & $\begin{array}{l}\text { Med"[journal] OR "J Clin Med"[journal] OR "Med J Aust"[journal] OR } \\
\text { "Palliat Med"[journal] OR Amyloid[journal] OR "Transl Res"[journal] OR } \\
\text { "Am J Med"[journal] OR "J Gen Intern Med"[journal] OR "Dtsch Arztebl } \\
\text { Int"[Journal][journal] OR "Am J Prev Med"[journal] OR "Br J Gen } \\
\text { Pract"[journal] OR "Ann Fam Med"[journal] OR "J Travel Med"[journal] } \\
\text { OR "Eur J Intern Med"[journal] OR "J R Soc Med"[journal] OR "Am J } \\
\text { Chin Med"[journal] OR "Prev Med"[journal] OR "J Pain Symptom } \\
\text { Manage"[journal] OR "Front Med (Lausanne)"[journal] OR "Ann } \\
\text { Med"[journal] OR "Pol Arch Intern Med"[journal] OR "J Formos Med } \\
\text { Assoc"[journal] OR "Br Med Bull"[journal] OR "Eur J Clin } \\
\text { Invest"[journal] OR "Pain Med"[journal] OR "Ups J Med Sci"[journal] OR } \\
\text { "Med Clin North Am"[journal] OR "Korean J Intern Med"[journal] OR } \\
\text { "QJM"[journal] OR "Int J Clin Pract"[journal] OR "Am Fam } \\
\text { Physician"[journal] OR "J Am Board Fam Med"[journal] OR "Diagnostics } \\
\text { (Basel)"[journal] OR "Minerva Med"[journal] OR "BMC Fam } \\
\text { Pract"[journal] OR "Arch Med Sci"[journal] OR "BMJ Open"[journal] }\end{array}$ & \\
\hline$\# 4$ & \#1 AND \#2 AND \#3 & \\
\hline
\end{tabular}


medRxiv preprint doi: https://doi.org/10.1101/2020.01.19.20018127; this version posted January 24, 2020. The copyright holder for this preprint (which was not certified by peer review) is the author/funder, who has granted medRxiv a license to display the preprint in perpetuity. It is made available under a CC-BY-ND 4.0 International license.

*excluded Cochrane Database of Systematic Reviews (11th ranking) search date 2019/12/01 
Table 3 data items

\begin{tabular}{|c|c|c|c|c|}
\hline Category & What? & How? & Who? & Cut-off \\
\hline \multirow[t]{11}{*}{ Description } & Number of paragraphs of & Simple counting & One review author & \\
\hline & background & & & \\
\hline & Number of cited articles in & Simple counting & One review author & \\
\hline & background & & & \\
\hline & Word counts in background & Simple counting & One review author & \\
\hline & Study type & Check visually & One review author & intervention \\
\hline & & & & $\begin{array}{l}\text { diagnostic test accuracy or } \\
\text { prediction }\end{array}$ \\
\hline & & & & prognostic \\
\hline & & & & prevalence \\
\hline & & & & other \\
\hline & Area of research & WOS API & Python with wos library & \\
\hline Exposure & Structure of background & Content analysis & Two review authors & \\
\hline \multirow[t]{7}{*}{ Confounders } & Number of included articles in SR & Check visually & One review author & Median \\
\hline & Number of tables and figures & Check visually & One review author & Median \\
\hline & Presence of practice implication in & Check visually & Two review authors & \\
\hline & discussion or background & & & \\
\hline & Number of authors & PubMed API & Python with biopython & Median \\
\hline & & & library & \\
\hline & Presence of appendix & Check visually & Single review author & \\
\hline
\end{tabular}


- SR: systematic review

- API: Application Programming Interface

- WOS: Web of Science 
References

1. $\quad$ Albert T. Winning the Publications Game. 4th ed. CRC Press; 2017.

2. Silvia PJ. Write it Up. 1st ed. American Psychological Association; 2019.

3. Bligh, Glennys Parsell J. AMEE Guide No. 17: Writing for journal publication. Med

Teach [Internet]. 1999 Jan 3;21(5):457-68. Available from:

http://www.tandfonline.com/doi/full/10.1080/01421599979121

4. Nwogu KN. The medical research paper: Structure and functions. English Specif

Purp. 1997;16(2 SPEC. ISS.):119-38.

5. Jirapanakorn N, Trakulkasemsuk W, Keyuravong S. Move Analysis of English

Research Article Introductions in Thai and International Medical Journals.

2014;17(June):23-40.

6. Guyatt G, Rennie D, Meade M, Cook D. Users' Guides to the Medical Literature: A

Manual for Evidence-Based Clinical Practice. 2nd ed. McGraw-Hill Professional;

2015.

7. Murad MH, Wang Z. Guidelines for reporting meta-epidemiological methodology

research. Evid Based Med [Internet]. 2017 Aug;22(4):139-42. Available from:

http://ebm.bmj.com/lookup/doi/10.1136/ebmed-2017-110713

8. InCites Journal Citation Reports [Internet]. [cited 2019 Oct 3]. Available from: 
https://jcr.clarivate.com/JCRLandingPageAction.action

9. Medicine I of. Clinical practice guidelines we can trust. 2011.

10. MECIR Manual | Cochrane Community [Internet]. [cited 2019 Oct 3]. Available

from: https://community.cochrane.org/mecir-manual

11. Force the USPST. Methods and Processes [Internet]. [cited 2019 Oct 3]. Available from:

https://www.uspreventiveservicestaskforce.org/Page/Name/methods-and-processes

12. Tahamtan I, Safipour Afshar A, Ahamdzadeh K. Factors affecting number of citations: a comprehensive review of the literature. Scientometrics.

2016;107(3):1195-225.

13. Rostami F, Mohammadpoorasl A, Hajizadeh M. The effect of characteristics of title on citation rates of articles. Scientometrics. 2014;98(3):2007-10.

14. Royle P, Kandala N-B, Barnard K, Waugh N. Bibliometrics of systematic reviews: analysis of citation rates and journal impact factors. Syst Rev [Internet]. 2013 Sep 12;2:74. Available from: http://www.ncbi.nlm.nih.gov/pubmed/24028376

15. Manriquez J, Cataldo K, Harz I. Factors influencing citations to systematic reviews in skin diseases: a cross-sectional study through Web of Sciences and Scopus. An

Bras Dermatol [Internet]. 90(5):646-52. Available from: 
http://www.ncbi.nlm.nih.gov/pubmed/26560209

16. Peduzzi P, Concato J, Kemper E, Holford TR, Feinstein AR. A simulation study of the number of events per variable in logistic regression analysis. J Clin Epidemiol

[Internet]. 1996 Dec;49(12):1373-9. Available from:

https://linkinghub.elsevier.com/retrieve/pii/S0895435696002363

17. Shea BJ, Reeves BC, Wells G, Thuku M, Hamel C, Moran J, et al. AMSTAR 2: a critical appraisal tool for systematic reviews that include randomised or non-randomised studies of healthcare interventions, or both. BMJ [Internet]. 2017 Sep 21;j4008. Available from: http://www.bmj.com/lookup/doi/10.1136/bmj.j4008 